\title{
The functionalized graphene oxide as new anti-cancer therapeutics
}

\author{
Natalia Krasteva \\ Electroinduced and Adhesive \\ Properties \\ Institute of Biophysics and Biomedical \\ Engineering, Bulgarian Academy of \\ Sciences \\ Sofia, Bulgaria \\ nataly@bio21.bas.bg \\ Bela Vasileva \\ Laboratory of Molecular Genetics \\ Institute of Molecular Biology "Acad. \\ R. Tsanev", Bulgarian Academy of \\ Sciences \\ Sofia, Bulgaria \\ belavas@outlook.com
}

\author{
Milena Keremidarska-Markova \\ Electroinduced and Adhesive \\ Properties \\ Institute of Biophysics and Biomedical \\ Engineering, Bulgarian Academy of \\ Sciences \\ Sofia, Bulgaria \\ m_keremidarska@abv.bg
}

George Miloshev

Laboratory of Molecular Genetics

Institute of Molecular Biology "Acad.

R. Tsanev", Bulgarian Academy of Sciences

Sofia, Bulgaria

karamolbiol@gmail.com

\author{
Kamelia Hristova-Panusheva \\ Electroinduced and Adhesive \\ Properties \\ Institute of Biophysics and Biomedical \\ Engineering, Bulgarian Academy of \\ Sciences \\ Sofia, Bulgaria \\ kameliahristova@abv.bg
}

Milena Georgieva

Laboratory of Molecular Genetics Institute of Molecular Biology "Acad. R. Tsanev", Bulgarian Academy of Sciences Sofia, Bulgaria milenageorgy@gmail.com

\begin{abstract}
Clinically, there is an urgent need to identify new therapeutic strategies for selectively treating cancer cells. One of the directions in this research is the search for biocompatible therapeutics which selectively target cancer cells. Here, we show that aminated graphene oxide (GO-NH$)$ nanoparticles obtained by two different methods - ammonia modification and hydroxylamine functionalization, demonstrate selectivity toward human colon cancer and hepatocellular cells. The amination by the two different methods leads to decrease in the size of GO-NH2 nanoparticles and their zeta potential thus assuring easier penetration through the cell membrane. After characterization of the biological activities of pristine and both aminated GO we have demonstrated strong cytotoxicity of ammonia-modified GO- $\mathrm{NH}_{2}$ toward colon cancer cells in a dosedependent manner while in hepatic cancer cells, HepG2, hydroxylamine-functionalized GO induced a weaker toxicity effect. We have presented evidence that the common cytotoxic effects of the aminated by the two protocols $\mathrm{GO}-\mathrm{NH}_{2}$ on hepatic cancer cells and colon cancer cells were due to cell membrane damage and increased ROS production while in colon cancer cells the ammonia modified NPs additionally induced DNA damage which was not detected in hepatic cancer cells. In the latter severe mitochondrial dysfunction was detected. Our studies discuss the possibilities of exploiting aminated graphene oxide as an anti-cancer therapeutic and as a drug delivery agent with certain selectivity toward different tumours depending on the mode of functionalization applied.
\end{abstract}

Keywords - cytotoxicity, genotoxicity, apoptosis, ammonia, hydroxylamine, HepG2, Colon 26 cells, nanoparticle functionalization, $\mathrm{GO}, \mathrm{GO}-\mathrm{NH}_{2}$

\section{Introduction}

Graphene oxide (GO) is one of the most explored 2D nanomaterials in the last years for cancer therapy [1]. GO has an extra-high capacity to bind aromatic drugs due to its large specific surface area and abundant oxygen-containing groups [2]. Besides, GO may induce the generation of reactive oxygen species (ROS) in cells, which is one of the main toxicological mechanisms of action of nanomaterials [3]. ROS generated from $\mathrm{GO}$ can alter biological macromolecules including proteins, cell membrane lipids, DNA and RNA resulting in initiation of numerous signal transduction pathways linked to inflammation, malignant transformation, proliferation, and apoptosis. Thus, exposure of cancer cells to GO can significantly contribute to cancer cell killing by enhancing the cytotoxicity effect exerted through the induction of DNA damage. Therefore, GO not only can function as an effective drug carrier but also can potentially exert inhibitory effects on tumour cells when used by itself. To improve the therapeutic effect of GO-based cancer therapy, the surface properties of GO can be modulated by chemical functionalization with different functional groups, biomolecules, polymers, etc. However, depending on the synthesis method, the physicochemical properties of the functionalized GO nanoparticles vary and could exert a palette of diverse effects on cells and tissues [4]. Here, we represent evidence for differential potential of two differently aminated GO nanoparticles (NPs) - by ammonia modification $\left(\mathrm{GO}-\mathrm{NH}_{2}\right)$ and by hydroxylamine functionalization (haGO- $\mathrm{NH}_{2}$ ) versus pristine $\mathrm{GO}$, to induce toxicity in two cancer cell types - Colon 26 (colon cancer) and HepG2 (hepatic cancer), examining their effect on cell proliferation ability, cell membrane, ROS production, DNA damage and cell cycle arrest.

\section{Experimental}

A. NPs characterization: the nitrogen content of NPs was determinated by X-ray photoelectron spectroscopy (XPS) and particle size distribution and zeta potential (ZP) - by a Nano Zetasizer.

B. Cell culture: A colorectal cancer cell line, Colon26 and a hepatocellular cancer cell line, HepG2 were purchased from American Tissue Culture Collection (ATCC) and were maintained in DMEM medium supplemented with $10 \%$ fetal calf serum and antibiotic/antimycotic solution at $37^{\circ} \mathrm{C}$ in a fully humidified atmosphere at $5 \% \mathrm{CO}_{2}$.

C. Toxicity assessment of pristine and aminated GO NPS: Cells were seeded in a concentration of $2 \times 10^{4} \mathrm{cell} / \mathrm{ml}$ in $24-$ well plates (for cytotoxicity assessment) and $1 \times 10^{5}$ cell $/ \mathrm{ml} \mathrm{ml}$ in 6-well plates (for genotoxicity assessment) and incubated 24 and 48 hours before to be exposed to pristine (Graphenea, Spain) and aminated GO NPs with increasing concentrations 
of $1,10,20$ and $50 \mu \mathrm{g} / \mathrm{ml}$. At the $24 \mathrm{~h}$ the cells were stained with FDA to visualize cell morphology; LDH assay was performed to detect cell membrane damage. Cell Counting Kit (CCK-8, Sigma-Aldrich) was carried out to measure cell proliferation at the $48 \mathrm{~h}$ of incubation with NPs. ROS production was measured at $24 \mathrm{~h}$ of NPs exposure by DCFADA analysis. FACS and Comet assay was used to determine DNA damage and cell cycle arrest.

\section{Resultats and Discussion}

The results from XPS measurements reveal $3.47 \%$ nitrogen content in ammonia-modified $\mathrm{GO}-\mathrm{NH}_{2}$ versus $1.86 \%$ in hydroxylamine-functionalized haGO- $\mathrm{NH}_{2}$ in addition to carbon, oxygen and traces of sulfur and zinc while in pristine GO were detected only carbon and oxygen. Zetasizer assay data showed that pristine GO NPs are a heterogeneous population including a main fracture with NPs size of 1,5-3.6 $\mu \mathrm{m}$ and a small percentage of NPs with size of 250-515 nm and $\mathrm{ZP}$ of $-24.5 \mathrm{mV}$. Aminated GOs were more homogenous with particles mean size of $578 \mathrm{~nm}$ for $\mathrm{GO}-\mathrm{NH}_{2}$ and $594 \mathrm{~nm}$ for haGO- $\mathrm{NH}_{2}$ as well as $\mathrm{ZP}$ of $38.5 \mathrm{mV}$ and $-12.28 \mathrm{mV}$, respectively.

The results from the FDA staining showed that GO and GO- $\mathrm{NH}_{2} \mathrm{NPs}$ altered the morphological appearance of Colon 26 cells only at the highest concentrations of $50 \mu \mathrm{g} / \mathrm{ml}$. In $\mathrm{HepG}_{2}$ cells no visible alterations in cell morphology were observed regardless the concentrations of haGO-NH 2 . Analysis of CCK data demonstrated a dose-dependent cytotoxic effect of aminated GO NPs in Colon 26 cells and HepG2 cells, much stronger in $\mathrm{HepG}_{2}$ cells (appr. 2 times). The lower concentrations of pristine GO (4- and $10 \mu \mathrm{g} / \mathrm{ml}$ ) have demonstrated a stimulating effect on $\mathrm{HepG} 2$ proliferation which could be referred to the "hormesis effect" but surprisingly, a stimulating effect on Colon 26 cell proliferation was noticed after exposure of the cells to the highest concentrations of pristine GO NPs $(20$-and $50 \mu \mathrm{g} / \mathrm{ml})$.

The results from evaluation of the ability of GO NPs to generate ROS after 24 hours exposure showed that in Colon 26 cells GO and GO- $\mathrm{NH}_{2}$ generated statistically significant amounts of ROS compared to the control at all tested concentrations, however the ROS production induced from $\mathrm{GO}-\mathrm{NH}_{2}$ was slightly higher compared to GO, while in HepG2 cells all tested concentrations of haGO- $\mathrm{NH}_{2}$ induced much higher production of ROS levels than those measured in nontreated cells and in GO-treated cells.

Analysis of LDH leakage revealed that only aminated GO NPs regardless of the amination method induced damage in the cell membrane integrity by which possibly induce cytotoxicity in tumor cells. In Colon26 cells certain genotoxicity of both types of GOs (at a concentration of 10 $\mu \mathrm{g} / \mathrm{ml}$ for $\mathrm{GO}$ and $50 \mu \mathrm{g} / \mathrm{ml}$ of amGO-NH${ }_{2}$ ) was detected. Further, FACS analysis of the probable mechanisms of this observed genotoxicity led to detection of high level of apoptosis in all tested probes, regardless the treatment of cells with pristine or animated GO nanoparticles while necrosis was at a very low rate. DNA damage of HepG2 cells treated with pristine GO and haGO- $\mathrm{NH}_{2}$ was very faint to almost insignificant after $24 \mathrm{~h}$ exposure to the nanomaterials. This points out to the fact that the mechanisms through which haGO-NH $\mathrm{N}_{2}$ NPs exert their biological activities on HepG2 cells are not centred in maintenance of the stability of the genome an its integrity but rather elsewhere. The last made us probe the functions of mitochondria in these cells. Results unambiguously demonstrated compromised mitochondrial functions as a result of haGO- $\mathrm{NH}_{2}$ treatment.

$\mathrm{GO}$ and ammonia modified GO-NH $\mathrm{N}_{2}$ were found to inhibit the proliferation of Colon 26 cells. A reduction in the percentage of cells in the G0-G1 phase of the cell cycle after incubation with GO-NH $\mathrm{N}_{2}$ was observed in these tumour cells. The last showed a concentration-dependent reduction in the number of cells in all cell cycle phases with the most pronounced reduction in the number of cells in the phase G0$\mathrm{G} 1$ at the higher used GO-NH $\mathrm{H}_{2}$ concentrations. These results suggest strong cytotoxic and to some extent slight cytostatic effect of the amimated GO, especially at the concentration of $50 \mu \mathrm{g} / \mathrm{ml}$. Similar effects were not observed in HepG2 cells treated with haGO-NH

TABLE 1. SUMMARIZES SOME PHYSICO-CHEMICAL CHARACTERISTICS OF GO$\mathrm{NH}_{2}$ AND HAGO-NH $\mathrm{N}_{2}$ AND COMPARES SOME OF THE OBSERVED BIOLOGICAL EFFECTS OF THE TWO TYPE OF AMINATED GOS ON TWO DIFFERENT TUMOR MODELS

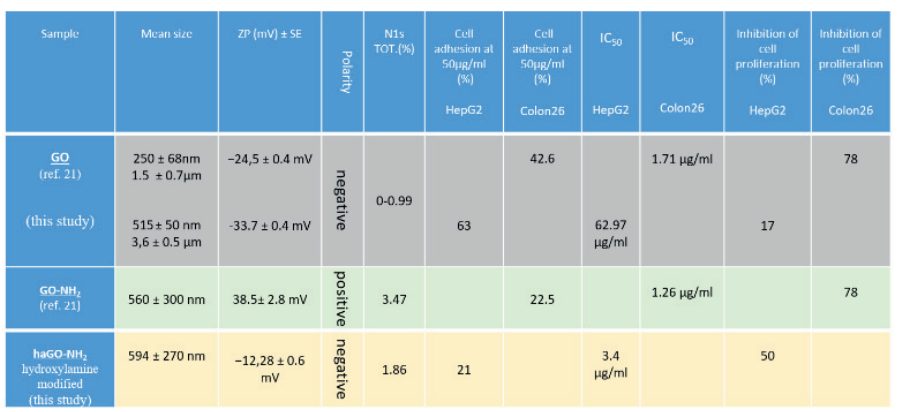

Conclusions

GO-NH $\mathrm{N}_{2}$ and haGO- $\mathrm{NH}_{2}$ have different physico-chemical properties as well as diverse modes of cyto- and genotoxicity in regard to the two types of tumour cells.

\section{ACKNOWLEDGMENT}

Funds from the Bulgarian Science Foundation - under Grants No. DNTS/ 01/6/2016 and KP06-N31/15.

\section{REFERENCES}

[1] G. Gonçalves, et al, "Nano-graphene oxide: a potential multifunctional platform for cancer therapy," Advanced Healthcare Materials, vol. 2, no. 8, pp. 1072-1090, 2013.

[2] M. Simsikova and T. Sikola, "Interaction of graphene oxide with proteins and applications of their conjugates," J of Nanomed Res., vol. 5 , no. 2, 2017

[3] M. Pelin, et al., "Graphene and graphene oxide induce ROS production in human HaCaT skin keratinocytes: the role of xanthine oxidase and NADH dehydrogenase, Nanoscale, vol. 10, no. 25, pp. 11820-11830, 2018.

[4] M. Xu, et al., "Improved in vitro and in vivo biocompatibility of graphene oxide through surface modification: poly(acrylic acid)functionalization is superior to PEGylation, ACS Nano, vol. 10, no. 3, pp. 3267-3281, 2016. 